Full length article

\title{
Application of millisecond pulsed laser for thermal fatigue property evaluation
}

\author{
Sining Pan ${ }^{\mathrm{a}, \mathrm{b}}$, Gang Yu ${ }^{\mathrm{a}, \mathrm{b}, *}$, Shaoxia $\mathrm{Li}^{\mathrm{a}}$, Xiuli He ${ }^{\mathrm{a}, \mathrm{b}}$, Chunyang Xia ${ }^{\mathrm{a}}$, Weijian Ning ${ }^{\mathrm{a}}$, Caiyun Zheng ${ }^{\mathrm{a}}$ \\ anstitute of Mechanics, Chinese Academy of Sciences, China \\ ${ }^{\mathrm{b}}$ School of Engineering Science, University of Chinese Academy of Sciences, China
}

\section{A R T I C L E I N F O}

\section{Article history:}

Received 19 January 2017

Received in revised form 2 May 2017

Accepted 12 September 2017

Available online 22 September 2017

\section{Keywords:}

Millisecond pulsed laser

Thermal fatigue

Cast iron

Crack evolution

\begin{abstract}
A B S T R A C T
An approach based on millisecond pulsed laser is proposed for thermal fatigue property evaluation in this paper. Cyclic thermal stresses and strains within millisecond interval are induced by complex and transient temperature gradients with pulsed laser heating. The influence of laser parameters on surface temperature is studied. The combination of low pulse repetition rate and high pulse energy produces small temperature oscillation, while high pulse repetition rate and low pulse energy introduces large temperature shock. The possibility of application is confirmed by two thermal fatigue tests of compacted graphite iron with different laser controlled modes. The developed approach is able to fulfill the preset temperature cycles and simulate thermal fatigue failure of engine components.
\end{abstract}

(c) 2017 Elsevier Ltd. All rights reserved.

\section{Introduction}

Thermal fatigue due to varying working temperature is one of the damage mechanisms that occur on the surface of engine combustion chamber components in the automotive industry [1,2], and is becoming serious with the development of higher power density engine. Therefore, it is of great importance to evaluate the thermal fatigue property under simulated thermal loading condition in the early conception stages. Two different kinds of temperature fluctuation range both exist in an internal combustion engine [3,4], which is $100-300^{\circ} \mathrm{C}$ with uncertain frequency and $20-50{ }^{\circ} \mathrm{C}$ with typical frequency of $1-10 \mathrm{~Hz}$. Several experimental methods with different heat sources have been developed to simulate and accelerate thermal damage, such as high frequency wire coil, localized flame, quartz lamp, and so on $[5,6]$. However, these heating methods show energy dispersity and difficulty in precise control.

Nowadays, laser is considered as a kind of ideal heat source due to its high spatial and temporal controllability [7]. Laser thermal fatigue experiments have been researched for the past few decades, and applied to rail steel, gas turbine, nuclear power plant, thermal barrier coating system and so on [8-11]. The current studies mainly focus on the fast heating features of continuous wave laser. Nevertheless, due to its intrinsic nature, it is difficult for

\footnotetext{
* Corresponding author at: Institute of Mechanics, Chinese Academy of Sciences, China.

E-mail address: gyu@imech.ac.cn (G. Yu).
}

the continuous wave laser to accomplish cyclic energy output in millisecond interval, especially for the engine conditions.

On the contrary, pulsed laser can realize energy output in pulse form, which has been widely used owe to its easy regulation of pulse duration, precise control of pulse repetition rate and high pulse energy [12]. Recently, the ultra-short pulsed lasers, which are with a few to dozens of nanosecond (ns), picosecond (ps) or femtosecond (fs) time durations, are attractive in evaluation of thermal and mechanical properties [13-15]. However, the extremely high peak power of ultra-short pulsed lasers would break down the surrounding material easily and cause undesired local surface damage. In addition, the characteristic time for heat conduction can be deduced from Fourier's heat conduction equation which is used to analyze the temperature evolution during thermal fatigue. It is expressed as a function of material properties, such as density, specific heat, characteristic body length and thermal conductivity approximately [16]. Taking the thermo-physical properties of general metals and the characteristic length of millimeter scale into account, the estimated characteristic time is of milliseconds order, which is consistent with the common working period of engine components. Therefore, a millisecond (ms) pulsed laser is more adaptable as heat sources for thermal fatigue experiments. As for the ms pulsed laser, the energy cumulative effect is noticeable when the pulse repetition rate is high enough, which reflects the thermal and mechanical effect of laser-material interaction. Consequently, the ms pulsed laser has aroused general concern and has been used in thermal fatigue test [17-19]. M. Schaus et al. [17] have performed the analyses on thermal shock and 
thermal fatigue properties of railroad steel sample by pulsed YAG laser with pulse duration of 15 ms. Muneharu Kutsuna et al. [18] have analyzed the life time of $\mathrm{Cr}$-Mo ferritic steel used for turbine housing after thermal fatigue test induced by ms pulsed laser. However, thermal fatigue tests with complex cycles using ms pulsed laser, especially designed for engine working conditions, have not been available in the scientific literature. Additionally, researches about the effects of laser parameters on the surface temperature response during thermal cycles are rarely reported.

Creatively, a novel approach of thermal fatigue experiment based on millisecond YAG pulsed laser is developed here, which can produce complex and transient temperature cycles. Particular emphasis is placed on the temperature change of compacted graphite iron with laser parameters, such as pulse energy, pulse duration and repetition rate, and the relationship is established for experimental parameter design. In addition, two experiments with different control modes are conducted, and the evolution process of thermal fatigue crack initiation and propagation is discussed.

\section{Experimental method and material}

\subsection{Basic principle of experimental method}

In order to simulate the cyclic response of thermal stress and strain, and analyze the initiation and propagation mechanism of thermal crack, appropriate and transient temperature gradients are expected to induce in the specimen according to actual conditions. Depending on the pulse waveform and combination of laser parameters, two different kinds of pulsed laser tests can be realized: laser irradiation with a high pulse repetition rate (Fig. 1(a1)) utilizing surface temperature accumulation effect for large thermal shock (Fig. 1(a-2)); heating to the maximum temperature

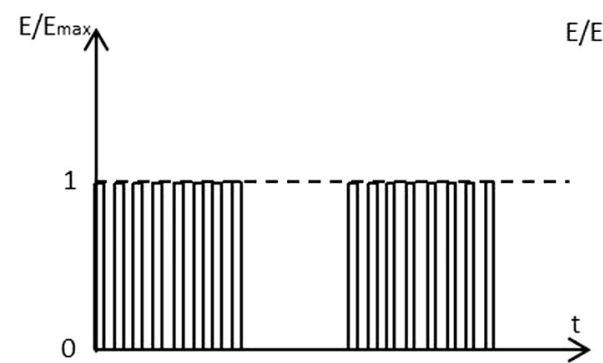

$(\mathrm{a}-1)$

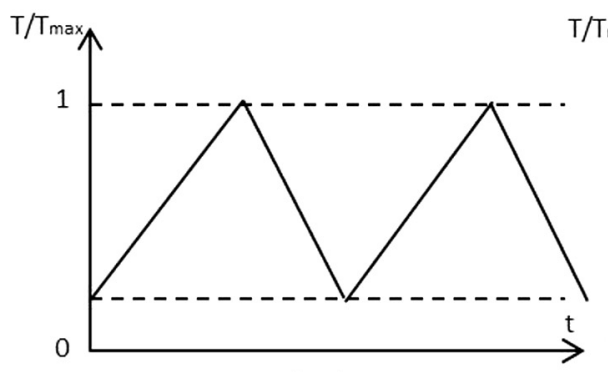

$(\mathrm{a}-2)$

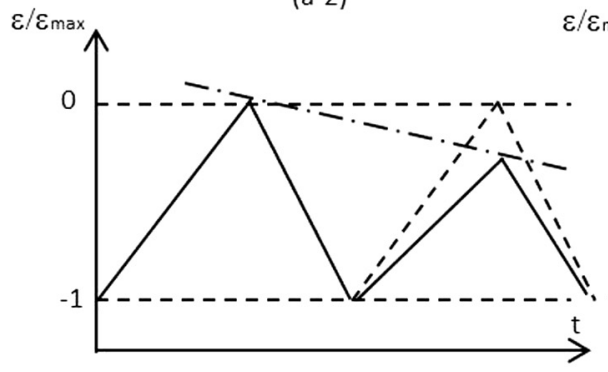

$(a-3)$

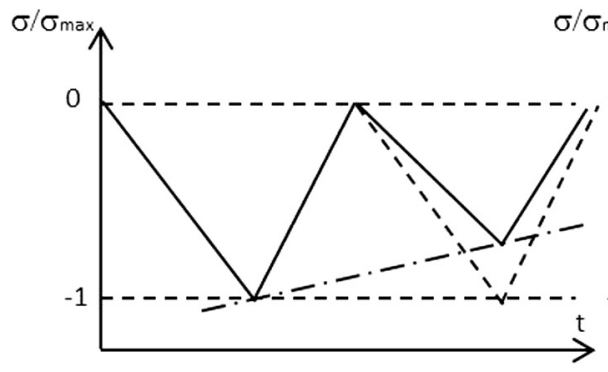

$(a-4)$

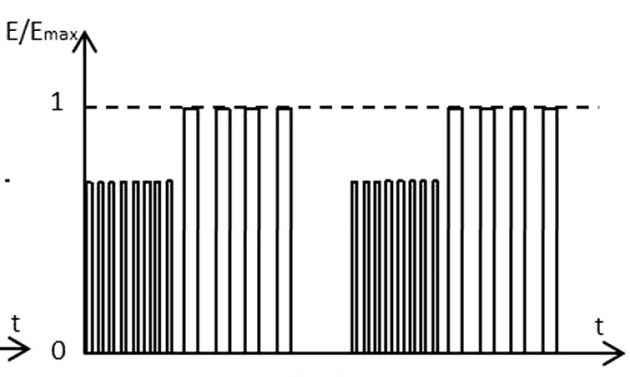

(b-1)

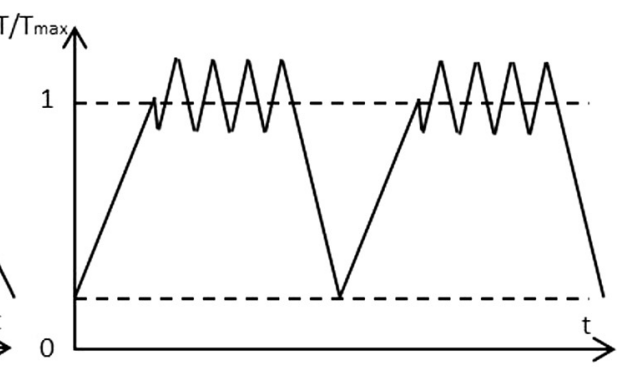

$(b-2)$

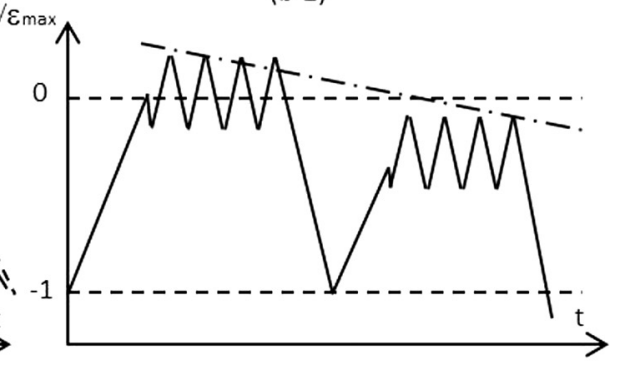

(b-3)

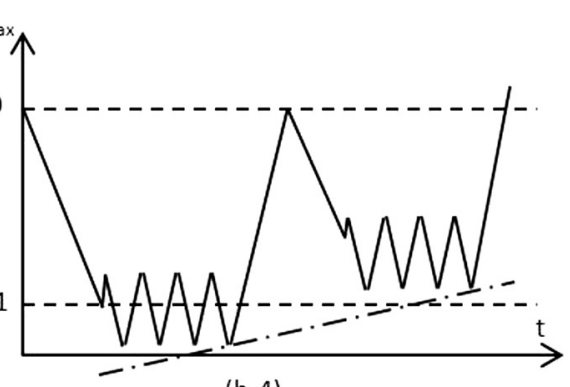

(b-4)

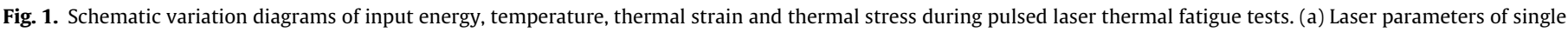
group; (b) combination form of laser parameters. 
with a high pulse repetition rate followed by small temperature oscillations using a low pulse repetition rate (as shown in Fig. 1 (b-1) and (b-2)). Such transient temperature gradients cause thermo-elastic strains and stresses, which are connected together based on the thermal expansion $\alpha$, temperature gradient $\Delta \mathrm{T}$ and Young's modulus E. Rapid heating of local sample surface makes the thermal expansion obstructed and produces compressive thermal stress, as demonstrated in Fig. 1(a-3) and (a-4). Similar phenomenon can be observed under the parameters combination of two groups, as presented in Fig. 1(b-3) and (b-4). Due to the surface heating feature of laser, there is still a large temperature gradient between the surface and substrate even at the end of heating phase. Once the local thermal stress exceeds the yield limit of material, plastic deformation occurs, resulting in irreversible thermal damage. If the thermal damage is accumulated to a certain extent, the thermal crack would begin to initiate and propagate, leading to thermal fatigue failure eventually.

To sum up, the basic principle of pulsed laser thermal fatigue test is, controlling energy distribution for inducing particular temperature field in specimen, producing a large temperature gradient which is based on the expansion obstruction and contraction obstruction, in order to accelerate thermal damage in dangerous areas.

\subsection{Experimental apparatus}

The developed apparatus allows to perform thermal fatigue test in a very flexible way, regardless of geometry and dimensions of the specimen, and to control the whole process with intelligence and automation. The schematic diagram of the proposed experimental apparatus is shown in Fig. 2, which includes a millisecond pulsed laser, temperature measure instrument, in-situ observation microscope, cooling recirculating device, sample holder and related control software.

Specifically, Nd:YAG Quantel IQL-10 pulsed laser with a wavelength of $1.064 \mu \mathrm{m}$ is applied in the test with the maximum pulse energy of $45 \mathrm{~J}$. The waveform of energy can be designed as square wave, triangle wave, sine wave or other type. Laser beam is delivered via optical fiber to the focusing output module, and irradiated at $10^{\circ}$ to the vertical direction of sample surface, in order to avoid back reflection to optical fiber and lens. The laser beam has a Gaussian energy distribution at the irradiated surface. By altering the working distance between sample and lens, the diameter of laser spot can be changed (a spot size of $8 \mathrm{~mm}$ in diameter here). The above adjustment is achieved by the inclination and up-down movement of the sample holder.

The temperature measure instrument includes contact and non-contact methods. Temperature in the center of laser spot on the sample surface is measured by an infrared pyrometer and fed back to the control software as a closed-loop control signal. Temperature in the base outside the laser irradiation area is recorded using several thermocouples. The in-situ observation microscope can provide the evolution process of sample surface during the experiment constantly. The information includes the distribution, density, length and width of cracks, which can be directly transmitted to the control unit for real-time analysis.

The cooling recirculating system is flexible to achieve the required cooling rate, by selecting the appropriate cooling medium such as compressed air, water and so on. The sample holder can be designed to accommodate any possibility for active cooling. As for air cooling of the specimen backside, a gas nozzle is set for the airflow guidance, which is controlled by a variable flowmeter through the PC software (as shown in Fig. 2). Another cooling method is putting the specimen on the copper block which is water cooled to keep the bottom temperature of specimen lower.

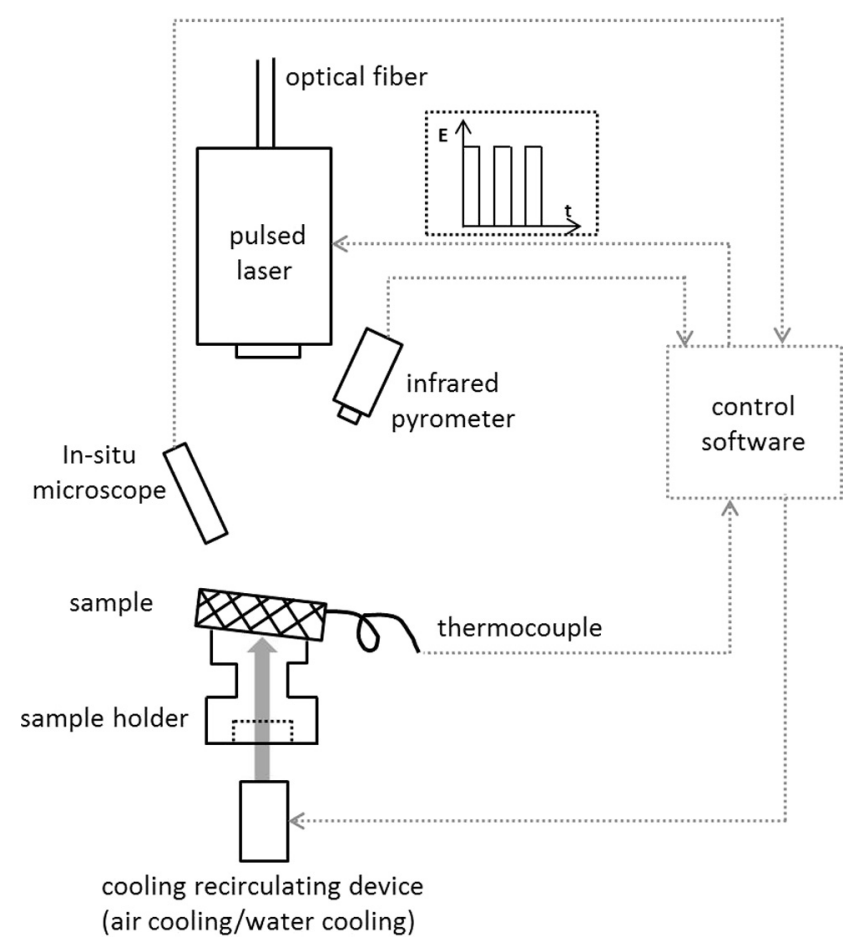

Fig. 2. Schematic diagram of the experimental apparatus.

The main function of control software is to record the temperature data and surface image, and to send operation instructions towards the laser and the cooling circulation system according to the chosen cycle mode. The fatigue test can be conducted in either time-controlled mode, or temperature-controlled mode, which the logic diagram is presented in Fig. 3. The former one is realized by setting heating duration $t_{h}$, cooling duration $t_{c}$ and holding time in a thermal cycle, while the latter one is achieved by setting maximum temperature $T_{\max }$, minimum temperature $T_{\min }$ and holding time. Whichever is chosen, the parameter setting of pulsed laser can be diverse in both pulse waveform and pulse parameters combination.

\subsection{Investigated material}

The tested material is compacted graphite iron (CGI), EN-GJV300 , which is common used in combustion chamber components of diesel engine, owing to its excellent thermal fatigue resistance. The chemical composition is given in Table 1. Surface morphology of the cast iron specimen is investigated by optical microscope. Fig. 4 shows the typical microstructure of un-etched sample surface before tests. Almost all the graphite phase is vermicular with average length of about $70 \mu \mathrm{m}$, and some spherical graphite scatters in the matrix.

\section{Results and discussion}

\subsection{Temperature response of different pulse energy}

In the following discussion, the data presented is measured with compressed air cooling $(10 \mathrm{~L} / \mathrm{min})$ at the bottom of specimen, if there is not noted specially.

When considering the influence of pulse energy on the surface temperature, the other parameters, i.e. pulse duration (10 ms), repetition rate $(1 \mathrm{~Hz})$, diameter of laser spot $(8 \mathrm{~mm})$ and testing time (60 s) are fixed. A low repetition rate is selected in order to present 


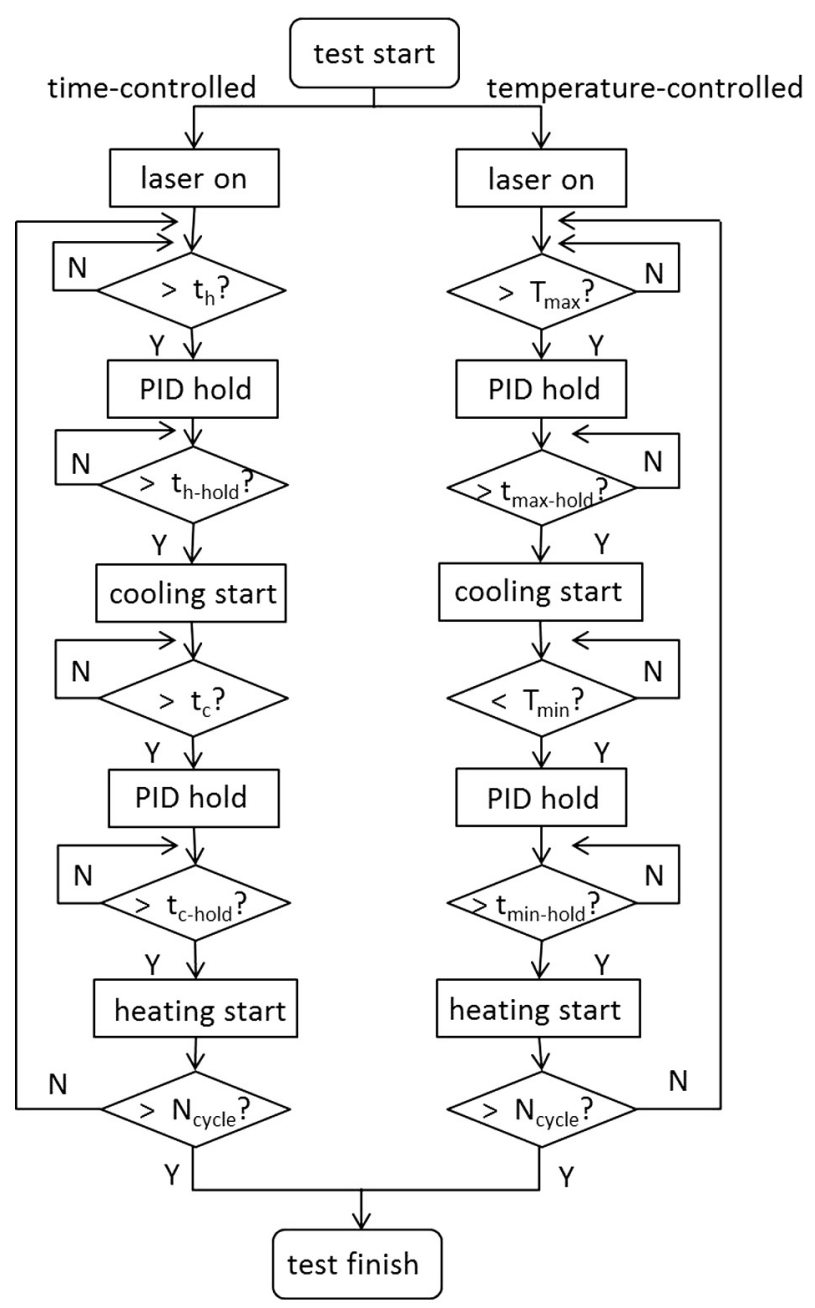

Fig. 3. Logic diagram of the control software.

the results clearly. Four values of pulse energy are tested: $5 \mathrm{~J}, 10 \mathrm{~J}$, $15 \mathrm{~J}, 20 \mathrm{~J}$, and the surface temperature curves with diverse pulse energy are demonstrated in Fig. 5. Although the base temperature measured by thermocouple (see dotted line in Fig. 5) increased gradually in the laser heating process due to the cooling limitation of compressed air, surface temperature fluctuation amplitude caused by each pulse is almost the same for a given energy. Therefore, the maximum and minimum value of each fluctuation can be identified separately and connected together, forming the upper envelope curve and the lower envelope curve (shown in Fig. 5). The average value of the difference between the upper and lower envelope is defined as the temperature fluctuation range (written as $\Delta \mathrm{T}$ ) caused by single pulse. It should be noted that, the first pulse energy is unstable, showing obviously smaller value than others, which should be excluded in the average calculation of $\Delta \mathrm{T}$.

Using the above method, each $\Delta \mathrm{T}$ corresponding to a specific energy level in Fig. 5 is calculated. Then, the correlation between temperature range $\Delta \mathrm{T}$ and pulse energy is revealed in Fig. $6 . \Delta \mathrm{T}$ caused by single pulse rises with the increasing energy, presenting a nonlinear relationship. As for the design of thermal high cycle fatigue (HCF) test with relatively small temperature oscillation of $20-50{ }^{\circ} \mathrm{C}$, thermo-elastic strain $\Delta \varepsilon$ and $\Delta \mathrm{T}$ is based on the connection with thermal expansion coefficient $\alpha$. Studies of the mechanical superimposed HCF effect on thermomechanical low cycle fatigue (LCF) property have been found in literatures [20-22], and the existence of HCF strain range threshold for three typical cast iron materials is proved. However, for the laser thermal fatigue test without mechanical loading or with constant mechanical loading, related research about the effect of thermal superimposed HCF on thermal LCF performance, and the threshold of thermal HCF strain range hasn't been reported yet, which will be the future working direction.

\subsection{Temperature response of different pulse duration}

In addition, the effect of pulse duration at different repetition rates is discussed. Assuming that pulse energy ( $5 \mathrm{~J}$ ) is keep constant, when the pulse width is set as $10 \mathrm{~ms}$ and $2 \mathrm{~ms}$, i.e., the peak power is increased five times, and results are revealed in Fig. 7. When the laser repetition rate stays at a low level, as shown in Fig. 7(a) and (b), cooling time of each pulse interval is long enough to eliminate the effect of higher peak power, so the heating behavior is almost the same. Since the repetition rate is up to $10 \mathrm{~Hz}$ or higher, as shown in Fig. 7(c) and (d), the temperature rises faster with shorter pulse width. With regard to the laser parameter design, the combination of shorter pulse duration and higher repetition rate is recommended for fast heating test.

\subsection{Temperature response of different repetition rate}

Furthermore, in order to assess the impact of repetition rate, study is carried out based on the same pulse duration $(10 \mathrm{~ms})$ and pulse energy ( $5 \mathrm{~J}$ ). Fig. 8 demonstrates the temperature-time curve of different repetition rates. From the low repetition rate curve like $1 \mathrm{~Hz}$ and $4 \mathrm{~Hz}$ (see the insert graph in Fig. 8), it can be seen that the surface temperature within the laser irradiated region shows periodic oscillation. The temperature rises rapidly at the beginning of laser pulse, and decreased sharply once the pulse is finished, which is consistent with the simulation results in literatures [23-25]. During laser irradiation, most of the laser energy is absorbed by the surface and converted into internal energy, resulting in a transient temperature increase on the surface. This phenomenon dominates over the conducted energy transportation from surface vicinity to solid bulk. After the end of pulse, the heat loss because of heat transfer to non-irradiated area, heat convection and radiation to environment, and then the surface temperature dropped suddenly. In the process of repetitive laser irradiation, the absorption of laser energy presents an intermittent heating effect. With the increase of pulse repetition rate (more than $8 \mathrm{~Hz}$ ), the temperature oscillation weakened gradually. When pulse repetition rate increases to a certain extent (almost $20 \mathrm{~Hz}$ ), the oscillation characteristics of temperature will disappear, and the temperature response behaves similarly as a continuous wave laser.

In the LCF experiments with a large thermal shock, in order to produce impressive temperature change between heating stage and cooling stage, further analysis of heating rate is needed. However, the cooling rate depends on the cooling medium and its flow rate, which will be discussed in the next section. The typical fast heating curve induced by pulsed laser is demonstrated in Fig. 9, testing by the following laser parameters: $5 \mathrm{~J}, 2 \mathrm{~ms}, 20 \mathrm{~Hz}$. As can be seen from it, in the early stage of laser irradiation, the surface temperature increases remarkably, due to the heat accumulation in a short time which is not able to transfer inward. In the next stage, heat conduction and thermal loading reaches a balance on the surface gradually, achieving a near-linear relationship between heating rate and time. The first stage is called "rapid heating stage" ("stage a" marked in Fig. 9), which covers the time from heating start $(0,0)$ to the beginning of near-linear increase $\left(t_{i}, T_{i}\right)$. The second stage is called "near-linear heating stage" ("stage b" marked in Fig. 9), covering the beginning of near-linear increase $\left(t_{i}, T_{i}\right)$ to heating end $\left(t_{m}, T_{m}\right)$. Therefore, the near-linear heating rate $v$ can be calculated with $\mathrm{v}=\left(\mathrm{T}_{\mathrm{m}}-\mathrm{T}_{\mathrm{i}}\right) /\left(\mathrm{t}_{\mathrm{m}}-\mathrm{t}_{\mathrm{i}}\right)$. 
Table 1

Measured chemical composition in weight percent of EN-GJV-300.

\begin{tabular}{|c|c|c|c|c|c|c|}
\hline$C$ & $\mathrm{Si}$ & $\mathrm{Mn}$ & $S$ & $\mathrm{P}$ & $\mathrm{Cu}$ & $\mathrm{Fe}$ \\
\hline 3.38 & 1.90 & 0.10 & 0.37 & 0.019 & 0.97 & Bal. \\
\hline
\end{tabular}

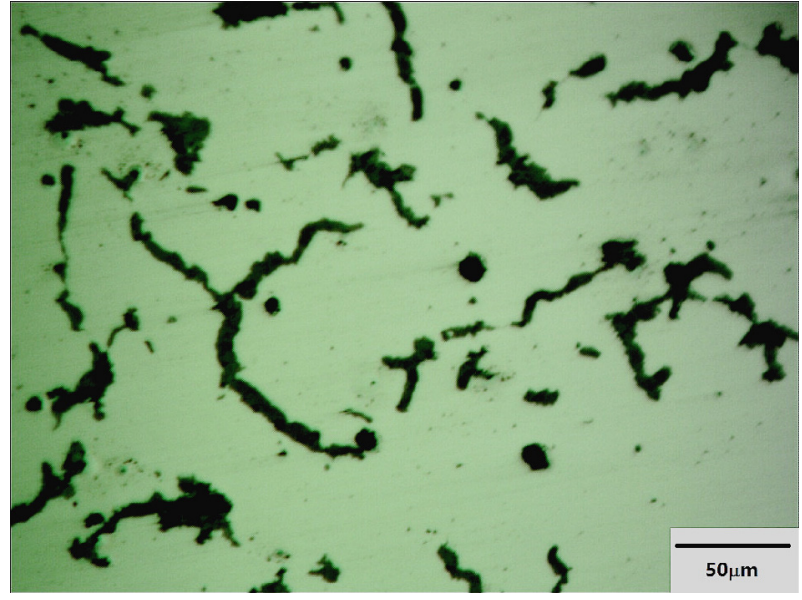

Fig. 4. Microstructure of specimen before thermal fatigue test (un-etched).
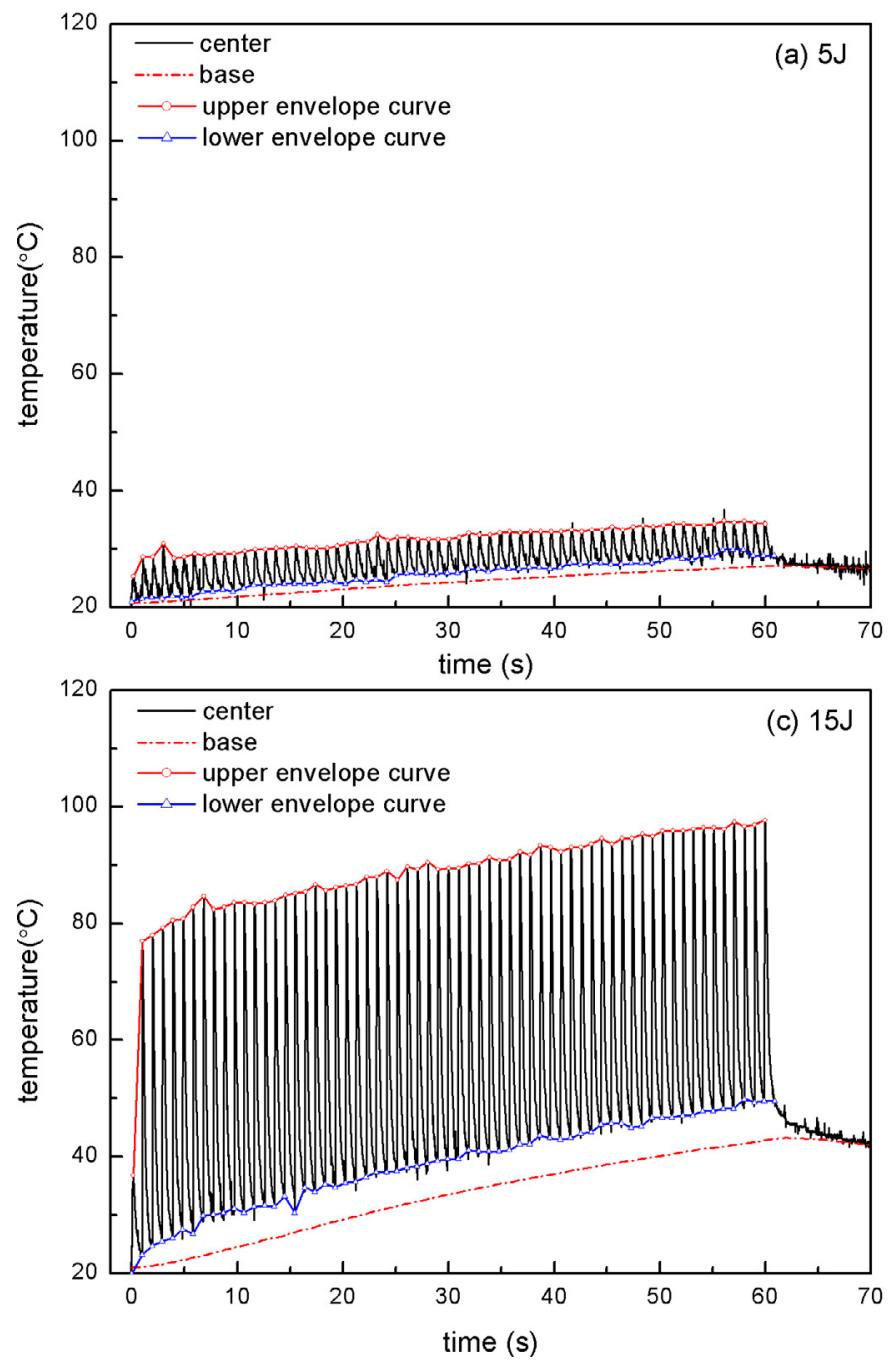

With regard to Fig. 9, since the pulse width and pulse energy are identical for specific material, the initial temperature of "stage b" $\left(T_{i}\right)$ increases with the augment of pulse repetition rate. Furthermore, similar behavior can be observed by changing the pulse width and pulse energy respectively. Taking pulse repetition rate as the horizontal axis, $T_{i}$ as the vertical axis, the above results are illustrated in Fig. 10. For a specific group of laser parameters, $T_{i}$ and repetition rate presents a linear increase trend. The slope can be obtained after linear fitting of experimental results, as the table shown in Fig. 10. The slope increases with higher pulse energy and shorter pulse duration. During the experimental parameters design, $T_{i}$ can be predicted according to the selected pulsed laser parameters, which is used as initial value for the final $T_{m}$ estimation.

Besides the $T_{i}$ value, when counting the maximum temperature $\mathrm{T}_{\mathrm{m}}$, the near-linear heating rate $\mathrm{v}$ is also required. The corresponding near-linear heating rate $\mathrm{v}$ in Fig. 10 is calculated, and the relationship between $\mathrm{v}$ and average power density is presented in Fig. 11. The reason for choosing average power density rather than
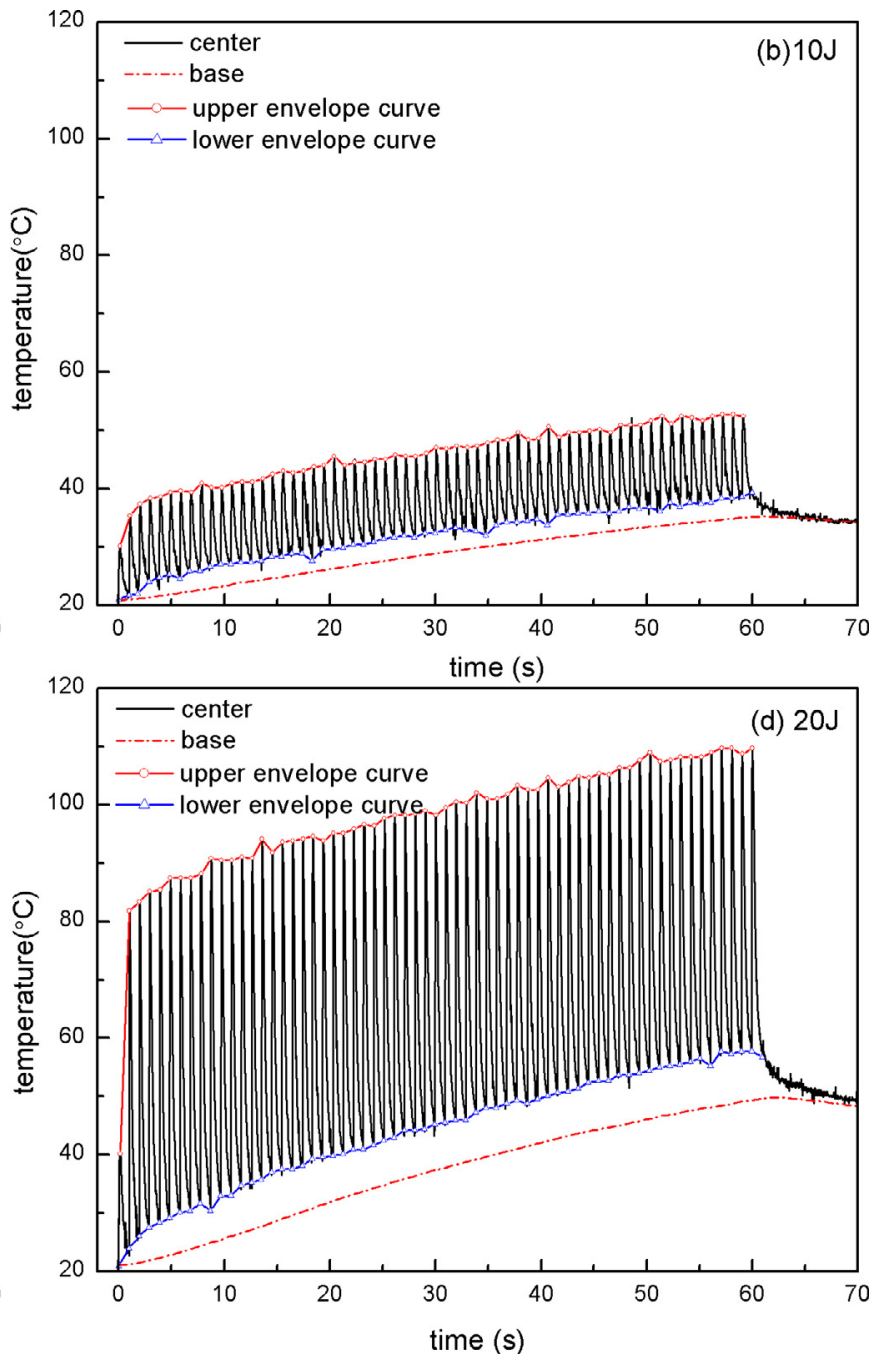

Fig. 5. Temperature curve with different pulse energy. 


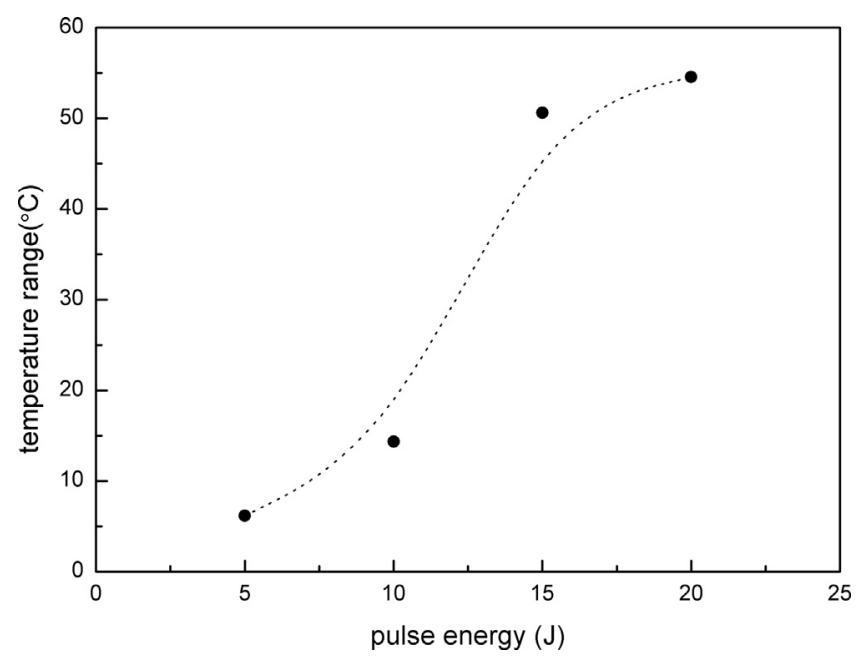

Fig. 6. Relationship between temperature range $\Delta \mathrm{T}$ and pulse energy.

peak power density as an independent variable $\mathrm{x}$, is because it considers the influence of pulse energy, pulse width and repetition rate generally. There is a linear relationship between them, and the fitting curve is also shown in Fig. 11 with dash line, which reflects the heating capacity of pulsed laser for a particular
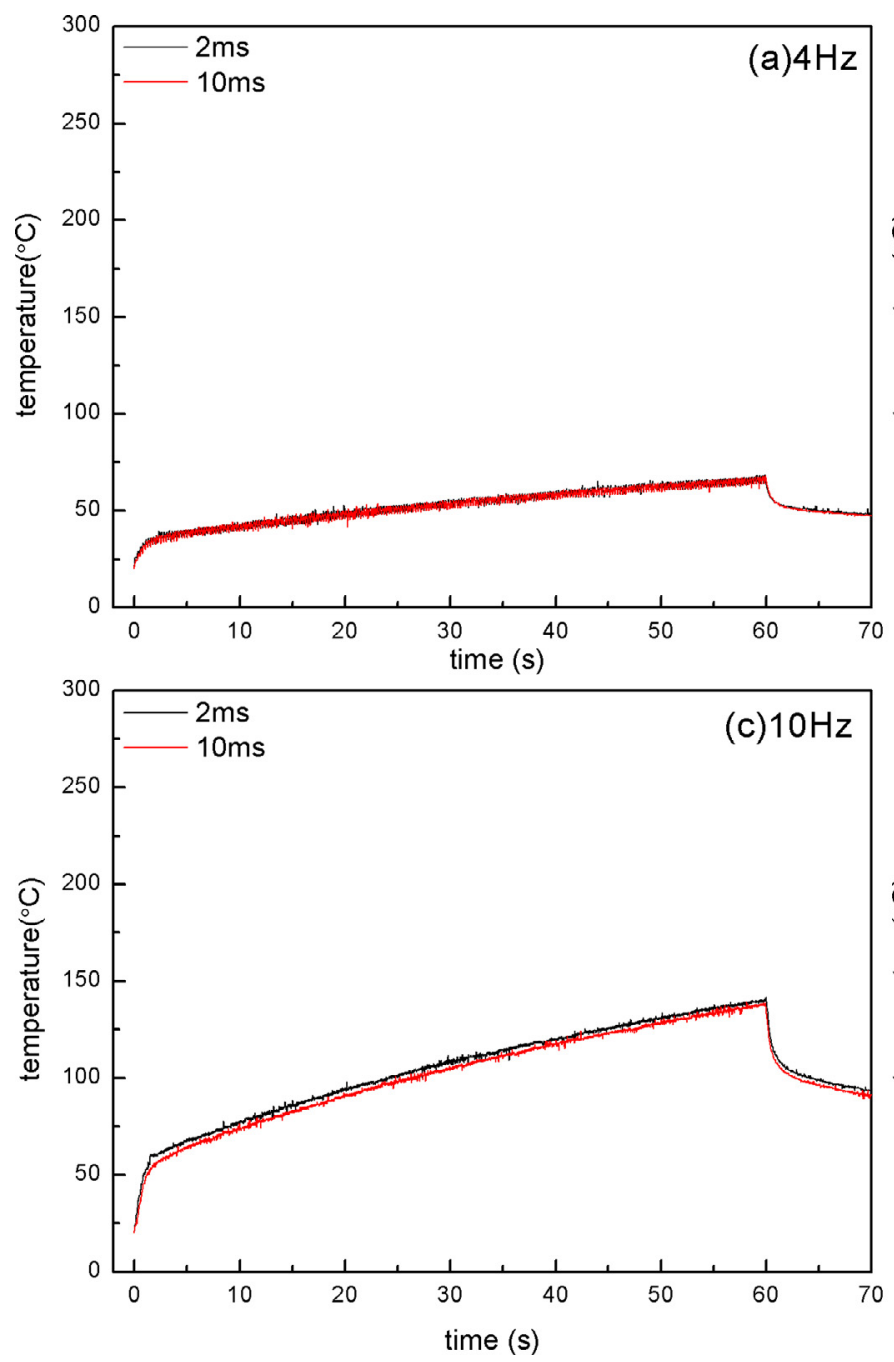

material. The required heating rate $\mathrm{v}$ can be estimated according to the maximum temperature $\mathrm{T}_{\max }$ and heating time $t_{\text {heat }}$ in a thermal cycle. In conclusion, appropriate pulsed laser parameters for LCF experiment with temperature range of $100-300{ }^{\circ} \mathrm{C}$ can be selected based on the above analysis.

\subsection{Thermal fatigue experiment with temperature-controlled mode}

The first thermal fatigue experiment is carried out on block sample (size of $10 \times 10 \times 25 \mathrm{~mm}^{3}$ ) made of EN-GJV-300 material. It is done using the proposed experimental system in Fig. 2, and conducted by PC programmed software with temperaturecontrolled mode. The surface temperature is set to change from $150{ }^{\circ} \mathrm{C}$ to $400{ }^{\circ} \mathrm{C}$. Backside air cooling is used to produce desired temperature gradient across the thickness direction. The laser pulse width, pulse energy and repetition rate are fixed to $2 \mathrm{~ms}$, $5 \mathrm{~J}$ and $20 \mathrm{~Hz}$ respectively, according the above analysis. The temperature curve of 10 cycles is demonstrated in Fig. 12. The thermal cycle loading exhibits repeatability by comparing the temperature values in different cycles. The temperature change range in the center of heating surface is $250^{\circ} \mathrm{C}$ as presetting, however, the temperature in the base of specimen shifts between $120^{\circ} \mathrm{C}$ and $210{ }^{\circ} \mathrm{C}$. As can be seen from Fig. 12, there is still temperature difference about $30{ }^{\circ} \mathrm{C}$ between the surface and the base even at the end of the cooling stage, mainly due to the cooling limitation of compressed air.
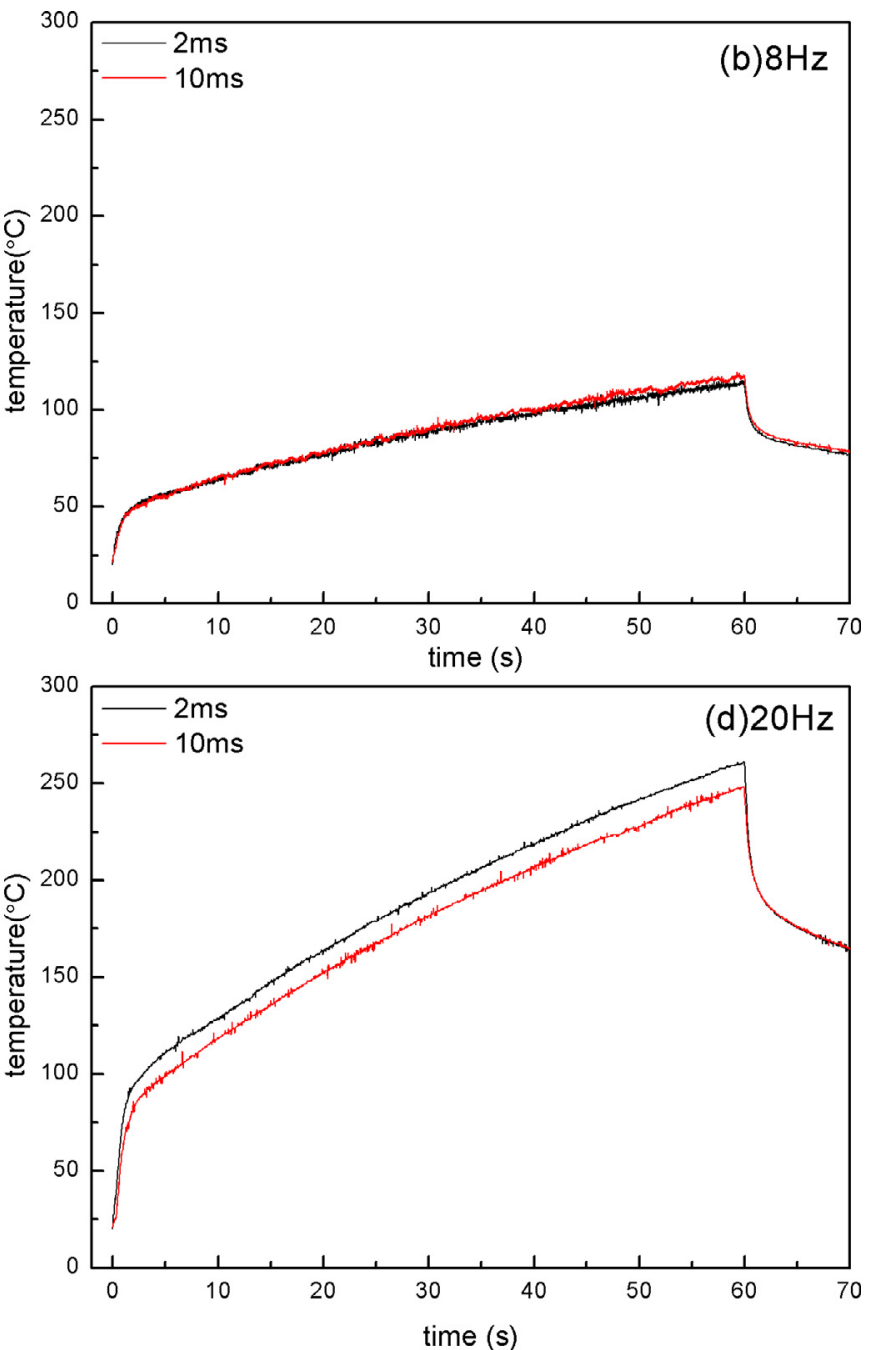

Fig. 7. Temperature curve with different pulse duration. 


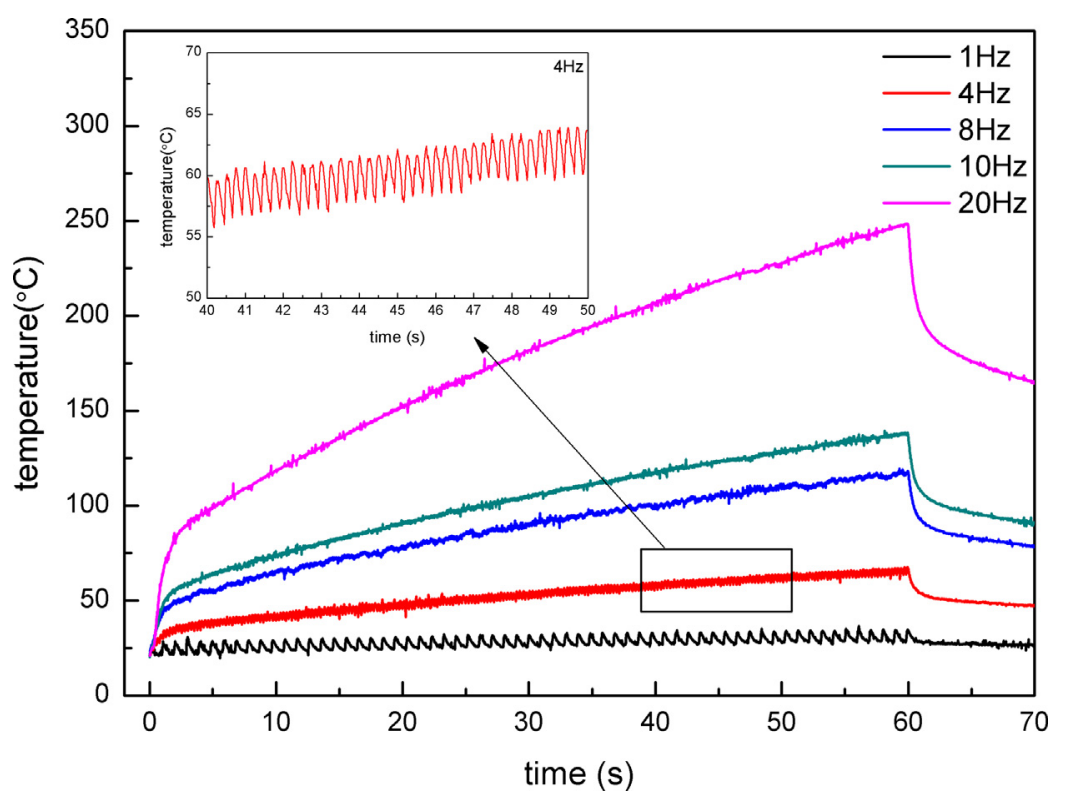

Fig. 8. Temperature curve with different repetition rate.

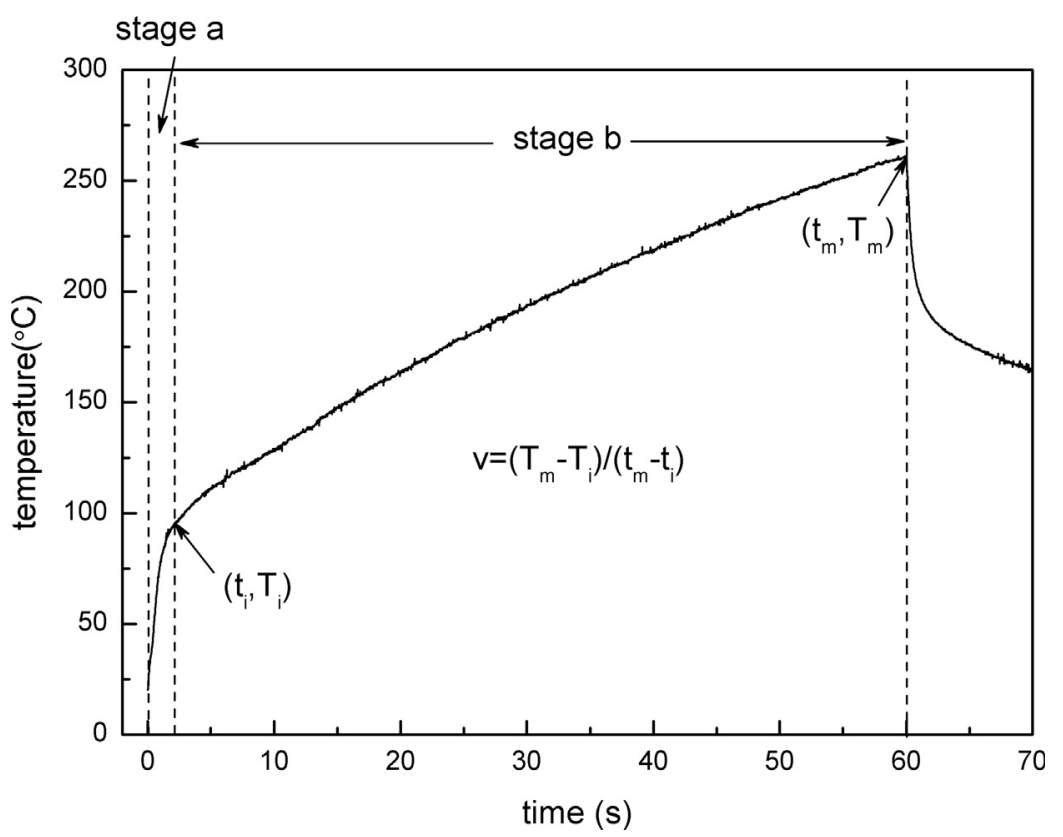

Fig. 9. Two stages of rapid heating process.

It is worth noting that, even the temperature-controlled mode is used, the heating time and cooling time of each cycle, except for the first cycle, is almost the same, which is about $30 \mathrm{~s}$ and $55 \mathrm{~s}$ respectively. In this experiment, only one group of laser parameters is used. Obviously, a variety combination of laser parameters, and waveform transform can be set up to achieve more complex loading style.

Surface crack is observed after 4500 cycles by optical microscope, as shown in Fig. 13. The sample surface is seriously oxidized (Fig. 13(a)) after long time exposure to high temperature environment in the air. Nevertheless, the thermal fatigue crack is still visible. After removal of the oxide layer, presented in Fig. 13(b), it is more clearly to observe the crack morphology and analyze the mechanism of crack formation. Extensive cracks with length of more than $300 \mu \mathrm{m}$ and width of $5-10 \mu \mathrm{m}$ are formed on the spec- imen surface. With high heat flux input and surface rapid heating by the pulsed laser, relatively large temperature gradient is induced across the depth direction of specimen during the whole thermal cycles. Especially at the beginning of cooling stage, the temperature discrepancy of different areas may reach $200^{\circ} \mathrm{C}$. Therefore, a high instantaneous tensile thermal stress on the heating surface is produced, even though the residual compressive stresses induced by laser heating are greatly reduced as compared to the uniform heating cases. These dynamic transient tensile thermal stresses may become a predominant driving force for crack propagation, mainly because of the fast dynamic loading characteristics near the crack tip. At the same time, the oxidizing gas penetrates into the metal matrix along the crack tip, causing severe internal oxidation and accelerating thermal fatigue failure process. 


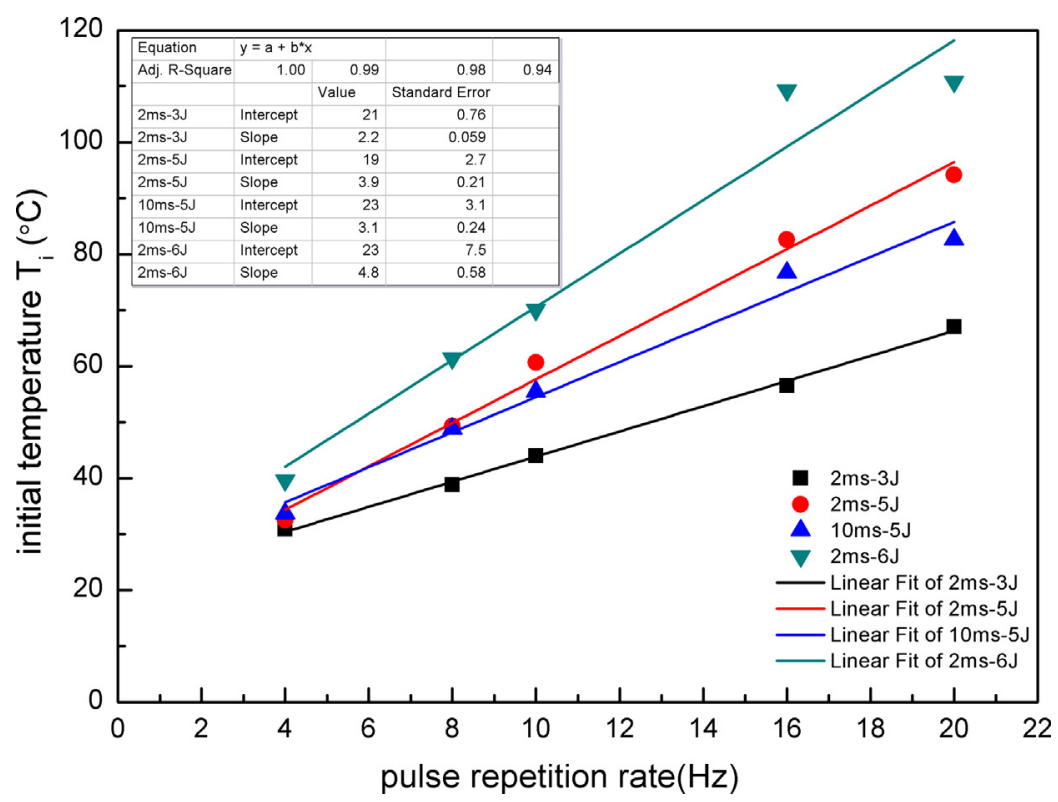

Fig. 10. Linear relationship between initial temperature $T_{i}$ and pulse repetition rate.

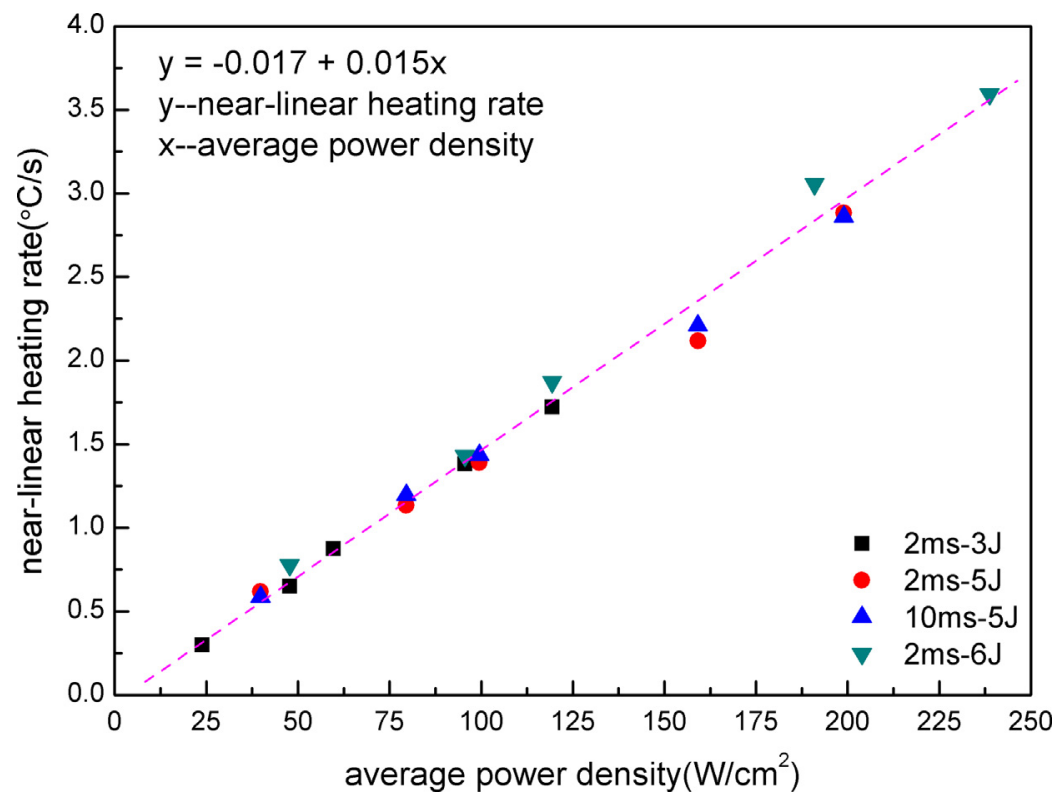

Fig. 11. Linear relationship between near-linear heating rate $\mathrm{v}$ and average power density.

\subsection{Thermal fatigue experiment with time-controlled mode}

The second experiment is conducted on cylinder sample (size of $\Phi 25 \times 10 \mathrm{~mm}^{3}$ ) manufactured with the same material as Section 3.4. The other settings, such as surface process, temperature measurement, heat source, are identical as the first example. The test is going on with time-controlled mode, which the heating and cooling time are both fixed to $60 \mathrm{~s}$. The laser parameters are set to $2 \mathrm{~ms}, 6 \mathrm{~J}$ and $30 \mathrm{~Hz}$ respectively. Considering the cooling limitation of compressed air, another cooling method which the specimen is put on a copper block with water cooled inside is applied. Fig. 14 shows the temperature curve of 10 cycles during the experiment process. These testing conditions generate maximum surface temperature swings from $30^{\circ} \mathrm{C}$ to $200{ }^{\circ} \mathrm{C}$, while the temperature fluctuation of the base is between $30^{\circ} \mathrm{C}$ and $80^{\circ} \mathrm{C}$. Owing to the improvement of cooling, the surface temperature decreases rapidly to almost the same as the base once the cooling phase begins, and then the whole specimen is cooled without temperature discrepancy until the end of cooling stage, resulting in the same starting temperature of heating stage for each cycle. Another effect of cooling medium change is the maximum heating temperature drops to $200^{\circ} \mathrm{C}$, which may not cause severe oxidation during the test.

The thermal crack development is demonstrated in Fig. 15, and no further polishing is made between the observation intervals in order to reflect the continuous process. Because of the existence of graphite, which can be seen from the original surface morphology in Fig. 15(a), the interface between metal matrix and graphite phase in cast iron provides potential crack source. After 100 cycles, several microcracks initiate at the tips of vermicular graphite, which are pointed out by arrows in Fig. 15(b). Due to stress concentration at the interface and thermal expansion mismatch, the cracks are easy to initiate at the graphite tip, and propagate along 


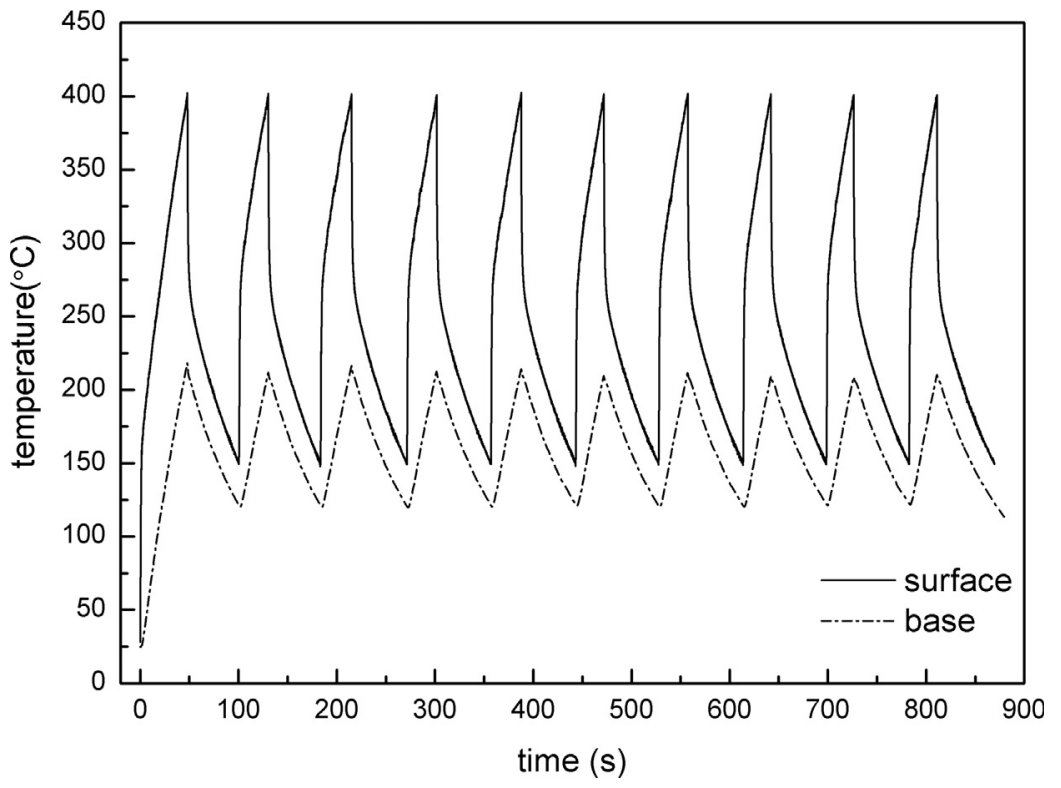

Fig. 12. Temperature curve of 10 cycles during the first experiment.

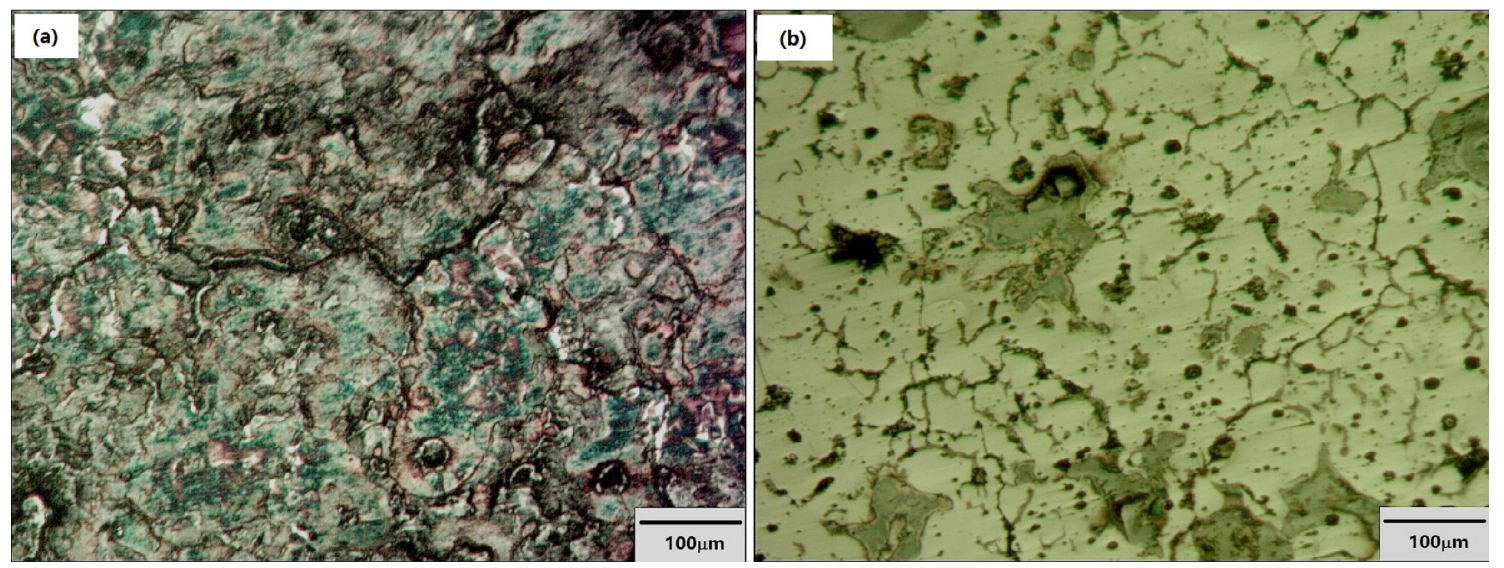

Fig. 13. Surface crack after 4500 cycles of the first experiment: (a) with oxide layer; (b) without oxide layer.

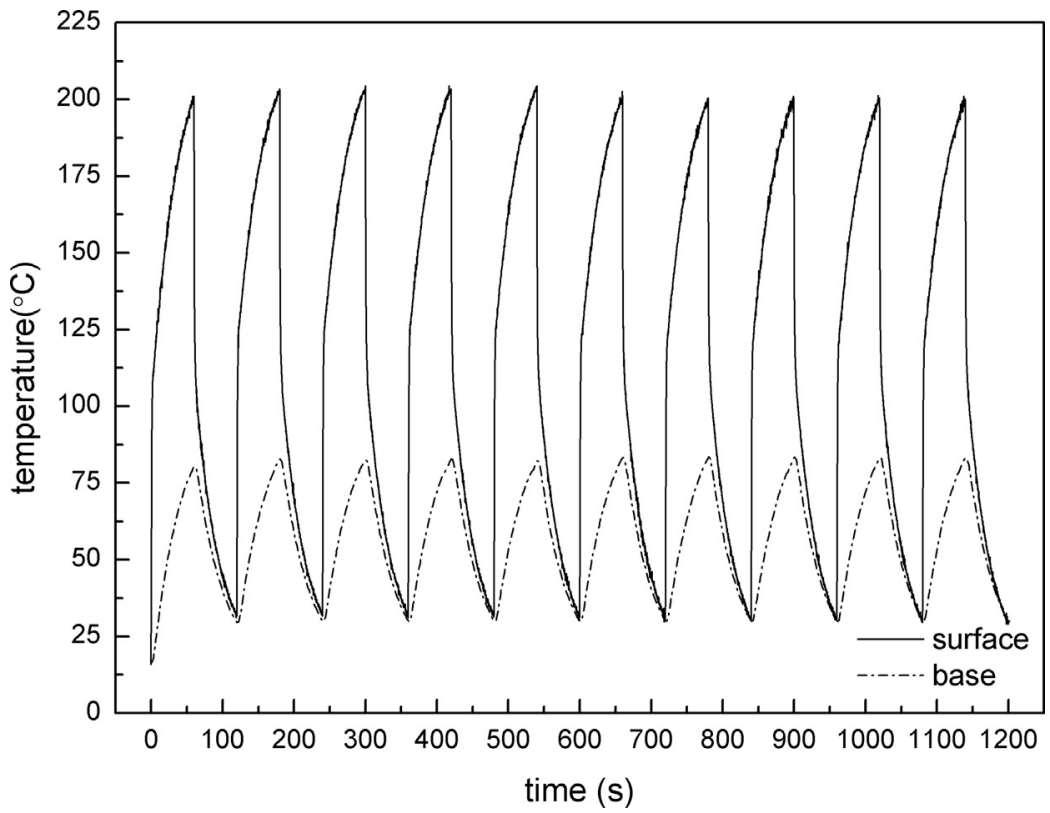

Fig. 14. Temperature curve of 10 cycles during the second experiment. 

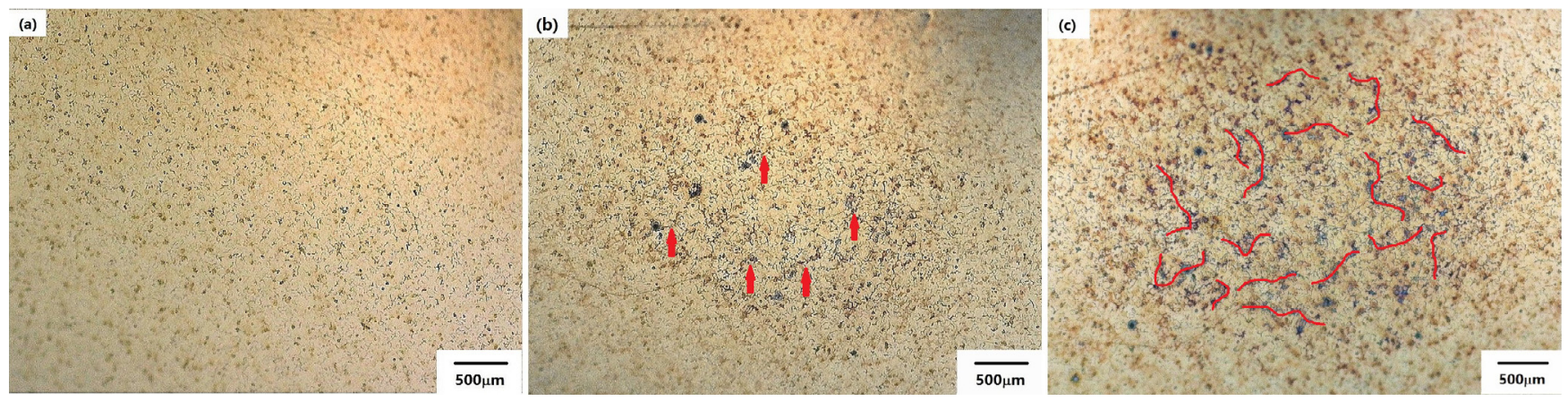

Fig. 15. Images of thermal cracks initiation process of CGI material. (a) Before tests; (b) after 100 cycles; (c) after 1000 cycles.

the graphite phases normal to applied stress [6,26]. Under the repeated loading of tensile stresses and compressive stresses generated in the thermal cycle, the graphite phases strip from the interface gradually. After 1000 cycles, several microcracks grow up and coalesce together to connect the adjacent graphite, forming macro cracks, which are highlighted in Fig. 15(c). Owe to the cooling improvement, the experiment period for crack formation is shorter than the former example.

From the above experiment results, it is seemed that the proposed method is possible to cause thermal fatigue on the specimen surface. It can be extended into other scientific fields, such as thermomechanical fatigue properties of heated parts in the macro scale, as well as analysis of defects evolution mechanism during thermal fatigue in the micro scale. Many kinds of metal materials, such as steel, superalloy, TBC system, etc., can be covered by the developed approach, and the same is for non-metallic materials, like advanced ceramics, thin films and so on. In addition to engine components, the experimental method can be applied to the aerospace, power systems, rail transport, advanced manufacturing and other areas suffering from thermal fatigue failures.

\section{Conclusions}

This paper proposes a novel thermal fatigue approach using millisecond pulsed laser heating, based on the thermal-mechanical effect of laser-material interaction, and the practical working conditions of engine components. Temperature cycle in complex form and transient response can be produced, causing thermal fatigue damage. A parameter selection principle of compacted graphite iron working under engine conditions is obtained. It is recommended to choose low pulse repetition rate $(1-3 \mathrm{~Hz})$ and high pulse energy (more than $10 \mathrm{~J}$ ) for a relatively small temperature range of $20-50{ }^{\circ} \mathrm{C}$, and the combination of high pulse repetition rate (more than $10 \mathrm{~Hz}$ ) and low pulse energy $(5-10 \mathrm{~J}$ ) is better for a large temperature change of $100-300{ }^{\circ} \mathrm{C}$. Two experiments of temperature-controlled mode and time-controlled mode respectively, are presented as typical application examples. It is proved that the proposed approach is able to induce controllable thermal loads and produce fatigue cracks by cyclic heating and cooling.

\section{Acknowledgments}

The authors are grateful for the supports from National Natural Science Foundation of China under grant Nos. 11272316, 11502269,11672304 and 11272317.

\section{References}

[1] B. Guo, W. Zhang, X. Wang, Failure analysis of a modern high performance diesel engine cylinder head, Adv. Mech. Eng. 6 (2015) 862853.
[2] T. Beck, D. Löhe, J. Luft, I. Henne, Damage mechanisms of cast Al-Si-Mg alloys under superimposed thermal-mechanical fatigue and high-cycle fatigue loading, Mater. Sci. Eng.: A 468-470 (2007) 184-192.

[3] R.A.M. Dongming Zhu, Investigation of thermal fatigue behavior of thermal barrier coating systems, Surf. Coat. Technol. 94-95 (1997) 94-101.

[4] S. Trampert, T. Gocmez, S. Pischinger, Thermomechanical fatigue life prediction of cylinder heads in combustion engines, J. Eng. Gas Turb. Power 130 (2008) 012806

[5] T. Tsuyoshi, K. Sasaki, Low cycle thermal fatigue of aluminum alloy cylinder head in consideration of changing metrology microstructure, Proc. Eng. 2 (2010) 767-776.

[6] X. Wang, W. Zhang, B. Guo, W. Zhao, The characteristics of microcrack initiation process in cast iron materials under thermal shock test, Mater. Sci. Eng., A 609 (2014) 310-317.

[7] S.G. Long, Y.C. Zhou, Thermal fatigue of particle reinforced metal-matrix composite induced by laser heating and mechanical load, Compos. Sci. Technol. 65 (2005) 1391-1400.

[8] V.S. Fantini, L. Serri, P. Bianchi, Laser thermal shock and fatigue testing system, Lasers Mater. Process. 3097 (1997) 538-545.

[9] J.D. Klod Kokini, Sudarshan Rangaraj, Brad Beardsley, Thermal shock of functionally graded thermal barrier coatings with similar thermal resistance, Surf. Coat. Technol. 154 (2002) 223-231.

[10] L. Vincent, M. Poncelet, S. Roux, F. Hild, D. Farcage, Experimental facility for high cycle thermal fatigue tests using laser shocks, Proc. Eng. 66 (2013) 669675 .

[11] Z. Gan, G. Yu, S. Li, X. He, R. Chen, C. Zheng, W. Ning, A novel intelligent adaptive control of laser-based ground thermal test, Chin. J. Aeronaut. 29 (2016) 1018-1026.

[12] Z. Zhang, P. Lin, S. Kong, X. Li, L. Ren, Thermal fatigue behavior of Mg-9Al-Zn alloy with biomimetic strengthening units processed by laser surface remelting, Opt. Laser Technol. 70 (2015) 1-6.

[13] J. Radziejewska, Application of a nanosecond laser pulse to evaluate dynamic hardness under ultra-high strain rate, Opt. Laser Technol. 78 (2016) 125-133.

[14] Z. Zhou, K. Zhang, J. Zhou, G. Sun, J. Wang, Application of laser ultrasonic technique for non-contact detection of structural surface-breaking cracks, Opt. Laser Technol. 73 (2015) 173-178.

[15] S.Z. Shuja, B.S. Yilbas, Laser heating of a moving slab: Influence pulse intensity parameter on temperature and stress fields, Opt. Laser Technol. 70 (2015) 716.

[16] Q. Tan, Dimensional Analysis, Springer, Verlag, Berlin, Heidelberg, 2011.

[17] P.M. Schaus, Nd-YAG-Laser simulated thermal shock and thermal fatigue behaviour of railroad steel, Metall 52 (1998) 464-470.

[18] M.F. Kutsuna, S. Fujita, Y. Sugita, K. Yamada, Thermal fatigue test for turbine housing by a pulse YAG laser, High-Power Lasers Manuf. 3888 (2000) 438445.

[19] M. Wang, Y. Li, Z. Wang, E. Bao, Effect of rare earth elements on the thermal cracking resistance of high speed steel rolls, J. Rare Earths 29 (2011) 489-493.

[20] M. Metzger, B. Nieweg, C. Schweizer, T. Seifert, Lifetime prediction of cast iron materials under combined thermomechanical fatigue and high cycle fatigue loading using a mechanism-based model, Int. J. Fatigue 53 (2013) 58-66.

[21] V. Norman, P. Skoglund, D. Leidermark, J. Moverare, Thermo-mechanical and superimposed high-cycle fatigue interactions in compacted graphite iron, Int. J. Fatigue 80 (2015) 381-390.

[22] V. Norman, P. Skoglund, D. Leidermark, J. Moverare, The effect of superimposed high-cycle fatigue on thermo-mechanical fatigue in cast iron, Int. J. Fatigue 88 (2016) 121-131.

[23] M.K.B.S. Yilbas, Analytical solution for pulsed laser heating process-convective boundary condition case, Int. J. Heat Mass Transf. 45 (2002) 1571-1582.

[24] M. Kalyon, B.S. Yilbas, Repetitive laser pulse heating analysis: pulse parameter variation effects on closed form solution, Appl. Surf. Sci. 252 (2006) 22422250.

[25] B.S. Yilbas, A closed form solution for temperature rise inside solid substrate due to time exponentially varying pulse, Int. J. Heat Mass Transf. 45 (2002) 1993-2000.

[26] M. Moonesan, A. Honarbakhsh raouf, F. Madah, A. Habibollah zadeh, Effect of alloying elements on thermal shock resistance of gray cast iron, J. Alloy. Compd. 520 (2012) 226-231. 